\title{
Endodontic retreatment of curved root canals using the dual wavelength erbium, chromium:yttrium, scandium, gallium, garnet, and diode 940-nm lasers and the XP-Endoshaper/finisher technique
}

\author{
Riman Nasher $^{1}\left(\mathbb{D} \cdot\right.$ Ralf-Dieter Hilgers $^{2} \cdot$ Norbert Gutknecht $^{1}$ \\ Received: 19 January 2020 / Accepted: 24 September 2020 / Published online: 8 October 2020 \\ (C) The Author(s) 2020
}

\begin{abstract}
Purpose The aim of this quantitative study was to compare between a dual-wavelength laser (Er,Cr:YSGG, diode $940 \mathrm{~nm}$ ) to the XP-Endoshaper/finisher combined with ethylenediaminetetraacetic acid (EDTA) 17\% technique in removing secondary smear layer created during endodontic retreatment of curved canals.

Methods Twenty-four human curved root canals were endodontically prepared and filled with AH-sealer and Reciproc® Gutta percha cones. The fillings were removed after 6 weeks, and the samples were randomly divided into 3 groups: A, negative control: irrigated with distilled water; B, XP-Endoshaper/finisher with EDTA 17\%; and C Er,Cr:YSGG (2 W, $20 \mathrm{~Hz}, 50 \mu \mathrm{s})$ and diode $940 \mathrm{~nm}$ ( $2 \mathrm{~W}, 50 \%$ duty cycle). The canals were split longitudinally, and a laser scanning microscope (VK-X100K, VK$\mathrm{X} 200 \mathrm{~K}$, Keyence, Osaka, Japan) was used to capture images with the magnification of $\times 1000$ from the canals. The images were scored by three blinded dentists using the Hülsmann scoring system, and a statistical analysis was carried out.

Results A significant difference between the apical regions of groups B and C $(p=0.0010)$ was observed, with group C showing a cleaner apical region. However, this difference is cancelled out when comparing all areas of the canals $(t=1.43$, df $21 p=$ $0.1663)$.

Conclusion Within the limitations of this study, it can be concluded that a dual laser wavelength protocol (Er,Cr:YSGG (2 W, $20 \mathrm{~Hz}, 50 \mu \mathrm{s})$ and diode $940 \mathrm{~nm}(2 \mathrm{~W}, 50 \%$ duty cycle) may be positive in removing the secondary smear layer formed during endodontic retreatment cases of curved root canals.
\end{abstract}

Keywords Dental lasers $\cdot$ Er,Cr:YSGG $\cdot$ Diode $940 \mathrm{~nm} \cdot$ Endodontic retreatment $\cdot$ Curved canals $\cdot$ Sealer removal

\section{Introduction}

Studies have reported that the success rate of endodontic retreatment lies at $74 \%$ [1]. This has been associated with one or more factors, including inadequate canal debridement, inadequate obturation, and complicated canal anatomy, all in turn result in the persistence of bacterial infection inside the root canal [2-4]. Traditionally, endodontic retreatment is

Riman Nasher

riman.nasher@rwth-aachen.de

1 Department of conservative, periodontal and preventive dentistry, University hospital RWTH Aachen, Pauwelsstrasse 30,

52074 Aachen, Germany

2 Department of Medical Statistics, RWTH Aachen, Pauwelsstrasse 19, 52074 Aachen, Germany performed by first removing the obturating material and sealer, followed by repeated canal preparation and irrigation with a suitable antimicrobial solution such as $\mathrm{NaOCl}$, which is reported to remove bacteria and promote healing in retreatment cases [5]. Another widely used endodontic irrigant is ethylenediaminetetraacetic acid (EDTA) which is capable of removing the inorganic component of the smear layer [6]. Following canal irrigation, the placement of intracanal medication such as calcium hydroxide is the traditional method used to combat the infective bacteria [7, 8]. However, it has been reported that calcium hydroxide dressing is not reliable in all cases, most importantly due to the varied root canal anatomy, in addition to the presence of bacteria inside dentinal tubules [9], and this may lead to reinfection and failed root canal treatment.

During endodontic retreatment cases, the obturating material is traditionally removed mechanically and the canal irrigated with the same endodontic treatment disinfecting 
irrigations such as $\mathrm{NaOCl}$ [10]. Different studies focusing on root canal retreatment concluded that rotary instruments are more effective in removing the obturating material than hand files $[11,12]$. Other studies found no significant difference in removing gutta percha using different rotary systems $[13,14]$. Moreover, a study found that the absence of the endodontic smear layer resulted in a more effective removal of calcium hydroxide, which is found in some sealing materials, from straight root canals using traditional irrigation methods and rotary instruments [15]. Furthermore, EDTA has been reported to be capable of removing endodontic sealer to a certain degree [16].

Based on their absorption spectrum, different lasers strike different targets. Erbium lasers which are absorbed in water and hydroxyapatite are capable of ablating dental hard tissues [17]. Several studies using different Er,Cr:YSGG settings endorsed the use of a the 2780-nm wavelength in removing remove the endodontic smear layer created during root canal treatment of straight canals [18-21]. Additionally, diode lasers emitting photons on the wavelength of $940 \mathrm{~nm}$ has been shown the ability to target bacteria located deep within the dental hard tissues by penetrating the latter [22]. Recent research has investigated the possibility of applying both wavelengths in an alternating mode to remove both organic and inorganic smear layer components, as well as removing the deeply embedded bacteria. Those studies have shown positive results in removing the endodontic smear layer from straight root canals [23]. Additionally, a recent study [24] reported positive smear layer removal results using a new dual wavelength Er,Cr:YSGG and diode $940 \mathrm{~nm}$ laser protocol during root canal treatment of curved root canals. The safety of those setting on the root surface, periodontal tissues, and the surrounding bone has also been reported [25]. No publications assessing the ability of the dual wavelength laser Er,Cr:YSGG and diode $940 \mathrm{~nm}$ laser in cleaning and disinfecting curved root canals in retreatment cases were found in the literature.

In our present study, we aim to investigate the effectiveness of the dual wavelength laser Er,Cr:YSGG and diode $940 \mathrm{~nm}$ in removing the endodontic sealer remnant and uncovering the dentinal tubules in curved canals in comparison with the XPEndoshaper and XP-Endofinisher coupled with 17\% EDTA.

\section{Materials and methods}

After consulting the statistical department at the RWTH Uniklinik-Aachen university and based on the outcome of the first part of our study [24], the number of samples was determined to be 24 human curved root canals. Teeth extracted due to periodontal reasons were collected, and the Patients' consent to use the teeth in our study was obtained. To ensure standardization, the crowns were dissected using a diamond saw and the root lengths were set to $10 \mathrm{~mm}$. All canals were prepared using the Reciproc ${ }^{\circledR}$ system (Reciproc ${ }^{\circledR}$, VDW GmbH, Munich, Germany) and obturated with AH Plus ${ }^{\circledR}$ sealer (DENTSPLY Maillefer, USA) and Reciproc ${ }^{\circledR}$ Gutta percha cones. All teeth were stored in thymol solution for 6 weeks to allow the sealer and gutta percha to bind with the canal walls. The fillings were then removed using manual hedstrom files ISO 25, and the canals were recapitulated with R25 Reciproc $\AA$ system to create a secondary smear layer. The roots were then longitudinally split using a diamond saw, and the mean canal curvature was $22^{\circ} \pm 6^{\circ}$. The samples were divided into three groups $(n=8)$ as shown in Table 1 .

Group A: served as the negative control group; the canals were irrigated with distilled water before obturation and after removing the gutta percha and reciprocating the canal.

Group B: XP-Endoshaper with distilled water, and XPEndofinisher with EDTA 17\%: the XP-Endoshaper was applied with distilled water and activated inside the canal for $60 \mathrm{~s}$ with a speed of $800 \mathrm{rpm}$ while being moved in an apicalcoronal direction. The XP-Endofinisher tip was then applied at $800 \mathrm{rpm}$ for $60 \mathrm{~s}$ using EDTA $17 \%$ as an irrigating solution; the XP-Endofinisher tip was applied in a continuous movement along the axes of the canal. This treatment was applied pre-obturation and after removing the gutta percha cones and reciprocation.

Group C: dual wavelength laser treatment: Using the RFT2 tip, each canal was treated for 1 laser cycle with a speed of $1 \mathrm{~mm} / \mathrm{s}$. The settings applied were Er,Cr:YSGG (2 W, $50 \mu \mathrm{s}$, $20 \mathrm{~Hz}$, water $80 \%$, air 30\%) and diode $940 \mathrm{~nm}$ laser (2 W, $50 \%$ duty cycle) [24]. Each sample received this treatment once before obturation and once after removing the gutta percha and reciprocation.

All procedures were performed in a water bath set to $37^{\circ} \mathrm{C}$ to mimic the human body temperature. Afterwards, the root canals were split longitudinally in half and examined under the 3D scanning laser microscope (VK-X100K, VK-X200K, Keyence, Osaka, Japan). Images were taken from the cervical, middle, and apical third of the canals, and the images were scored by three blinded dentists using a scoring system originally described by the Hülsmann et al. [26] as follows:

Score 1: clean canals with all dentinal tubules uncovered and no trace of smear layer

Score 2: most of the dentinal tubules are visible; few areas are covered with smear layer

Score 3: canal covered with a smooth homogeneous smear layer, few visible dentinal tubules

Score 4: canal entirely covered with a smooth homogeneous smear layer, no visible dentinal tubules

Score 5: unclean canal covered with a heavy nonhomogeneous smear layer 
Table 1 The pre- and post-obturation procedures of the three study groups A, B, and C

\begin{tabular}{lll}
\hline Group & Pre-obturation treatment & Post-obturation treatment \\
\hline A & Irrigated with distilled water & Irrigated with distilled water \\
B & XP-Endoshaper/finisher & XP-Endoshaper/finisher \\
& $17 \%$ EDTA $^{\dagger}$ irrigation & $17 \%$ EDTA irrigation \\
C & Er,Cr:YSGG $: 2(\mathrm{~W}), 20(\mathrm{~Hz}), 50(\mu \mathrm{s}), 80 \%$ Water, $30 \%$ Air diode & Er,Cr:YSGG $: 2(\mathrm{~W}), 20(\mathrm{~Hz}), 50(\mu \mathrm{s}), 80 \%$ Water, $30 \%$ Air diode \\
& $940 \mathrm{~nm}: 2(\mathrm{~W}), 50 \%$ duty cycle & $940 \mathrm{~nm}: 2(\mathrm{~W}), 50 \%$ duty cycle \\
\hline
\end{tabular}

${ }^{\dagger}$ Ethylenediaminetetraacetic acid

${ }^{\star}$ Erbium, chromium, yttrium, aluminium, scandium, gallium, garnet

\section{Statistical analysis}

Hülsmann scores were described by mean and standard deviation statistical values. A linear mixed effects model was fitted to the response variable Hülsmann score with random intercept by sample within group and area, and random intercept and dentist by sample within group. The fixed effects were area, dentist, group, and the corresponding two-way interactions. We used linear contrast to assess differences for specific questions. The significance level was set to 5\%. SAS statistical software was used for computations, and proc mixed was used for the model fitting.

\section{Results}

\section{Microscopic results}

Figure $1 \mathrm{a}, \mathrm{b}, \mathrm{c}$ is a representation of the control group $\mathrm{A}$ in the cervical, middle, and apical thirds, respectively. The canal walls show a heavy, non-homogeneous smear layer with no detectible dentinal tubules. All parts of the canal were given score 5 by the 3 dentists. Figure 2a, b, c is a sample image taken from group B, treated with the XP-Endoshaper and XPEndofinisher coupled with 17\% EDTA, the canal shows very clean cervical and middle thirds and no trace of smear layer, and a relatively clean apical third with some smear layer remnants. The apical third was given Hülsmann scores between 1 and 3 , while one apical third received a score 4 . The results of the laser group $\mathrm{C}$ are shown in (Fig. 3a, b, c); the dentinal tubules are exposed in all three thirds of the canal, with a few traces of smear layer in the apical third. In this group, the Hülsmann scores ranged between 1 and 2, and only one apical third received score 3 , indicated a homogeneous smear layer covering the walls with a few visible dentinal tubules.

\section{Statistical results}

Table 2 exhibits the statistical results of the three study groups. The $p$ value was set to $(p<0.0001)$. There were no significant differences related to the score givers; however, significant differences between areas $(\mathrm{F}=19.91, \mathrm{p}<0.0001)$, groups $(F=454.81, p<0.0001$, and groups differ within areas $(F=$ $10.67, p<0.0001)$ were observed. Regarding the overall cleanliness of the canals, the laser group $\mathrm{C}$ was slightly more homogeneous across all areas than the group of the XPEndoshaper and finisher group B. A statistically significant difference between both groups $\mathrm{B}$ and $\mathrm{C}$ was observed in the apical region $(p=0.0010)$. In this region, the apical third group $\mathrm{C}$ received a Hülsmann score of 2.0000 , whereas the same area in group B was scored with 2.7500 .

\section{Discussion}

This study is a quantitative investigation of the effectiveness of the dual wavelength laser Er,Cr:YSGG and diode $940 \mathrm{~nm}$ laser in removing the smear layer created during endodontic
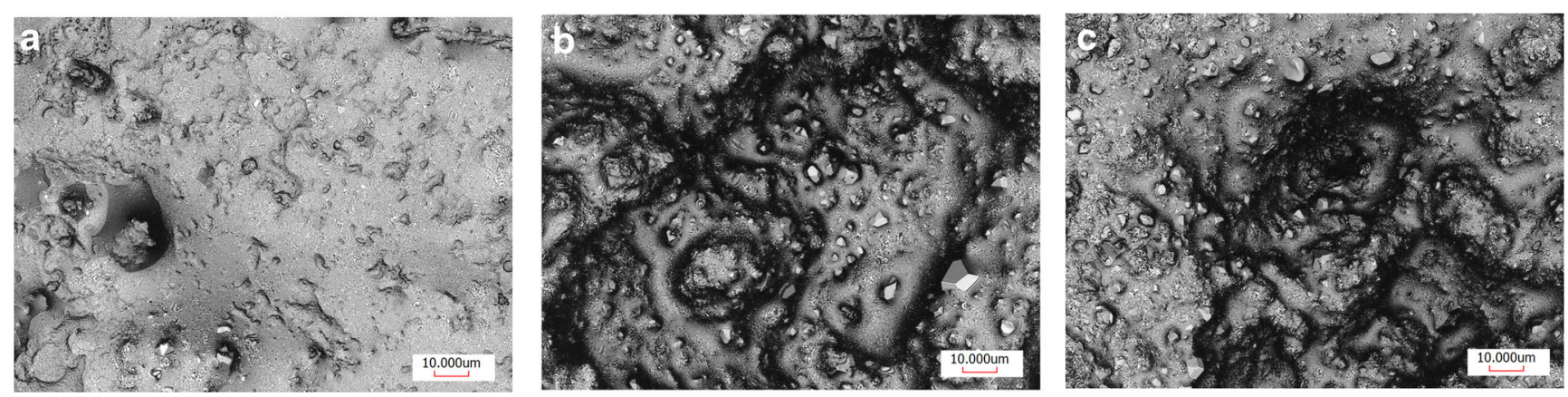

Fig. 1 a, b, c The cervical, middle, and apical regions of the control group A, respectively 

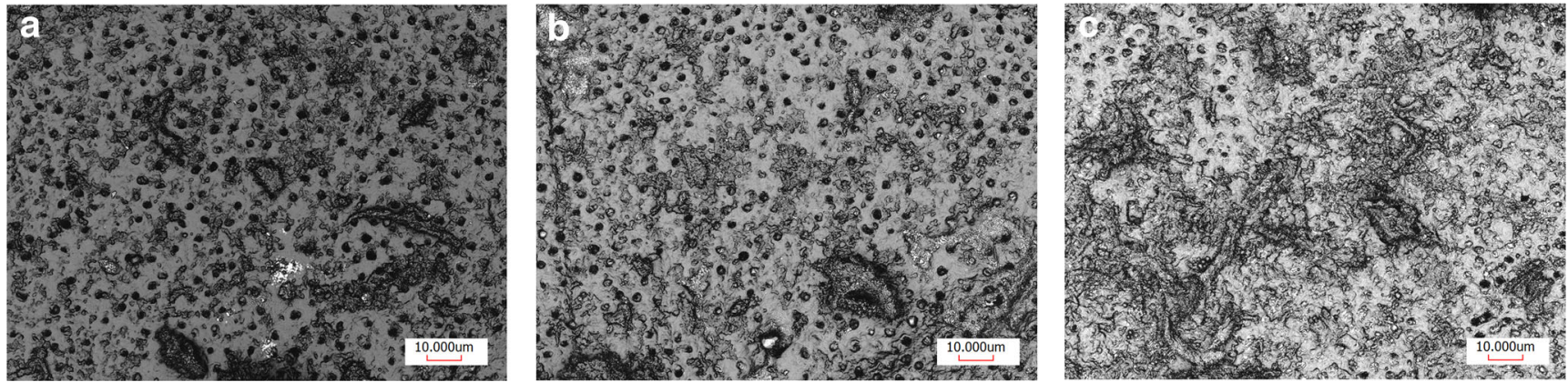

Fig. 2 a, b, c The cervical, middle, and apical regions of the XP-Endoshaper and XP-Endofinisher group, respectively

retreatment of curved root canals, which contains dentin debris and AH-plus sealer remnants, and exposing the dentinal tubules. We compared the results of group $\mathrm{C}$ where the laser was used to those of group B, treated with EDTA 17\% activated with the XP-Endoshaper and XP-Endofinisher tips. Our in vitro experiment revealed clean canals in the cervical and middle thirds of both groups $\mathrm{B}$ and $\mathrm{C}$, with a significantly cleaner apical third in group $\mathrm{C}$.

Removing the endodontic obturating material is an important factor in determining the success or failure of root canal retreatment procedures [27]. Previous studies affirmed the positive cleaning ability of rotary instruments in removing the endodontic gutta percha [28, 29], which agrees with the results of our study. However, it has been observed that using rotary instruments alone to remove the obturating material will not expose the dentinal tubules [30]. In our study, we focused on extensively re-instrumenting the canals with the Reciproc ${ }^{\circledR}$ files which resulted in creating a new smear layer observed heavily in the control group A, agreeing with Latheef et al. [30].

A study reported that the XP-Endoshaper and XPEndofinisher are capable of partially removing residual root canal obturating materials from straight root canals [31]. Another study reported an improvement in removing the obturating material from curved root canals [32] when applying the XP-Endofinisher tips after removal with rotary systems; the authors however did not specify whether the sealer was completely removed and the dentinal tubules were fully exposed.
Positive results have been reported regarding the debridement effect of different Er,Cr:YSGG laser setting combinations in straight root canals $[18,19,33]$. Additionally, it has been shown that the combined use of the Er,Cr:YSGG and diode $940 \mathrm{~nm}$ lasers provide an effective and safe method in removing the smear layer and simultaneously disinfecting straight canals $[23,34,35]$. The lasers settings tested in the present study have previously shown positive outcomes in removing the dental smear layer from curved root canals in endodontic treatment cases [24]. However, no study has been found regarding the effect of the alternate application of these wavelengths in dental retreatment investigations.

Furthermore, it seems that most endodontic laser studies continue to focus their attention on the effect of lasers in straight canals, even though around $84 \%$ of root canals have a certain degree of curvature [36]. In terms of the laser's capability in cleaning the apical third of curved root canals, our results agree with those of Alamoudi et al. who applied the $\mathrm{Er}, \mathrm{Cr}$ :YSGG laser in simulated curved canals ( $20^{\circ}$ curvature) filled with red fuchsine dye. In their work, the authors described a positive dye removal from the apical region using both circular and pulling tip movements and different settings combination [37].

In addition to removing secondary smear layer and uncovering the dentinal tubules, our study focused on laser tip preservation by applying only one laser cycle per canal. However, in 4 out of 8 cases, some burnt debris and remnants were observed on the RFT2 laser tip. This could be attributed to the use of the R25 Reciproc ${ }^{\circledR}$ file, which might have been
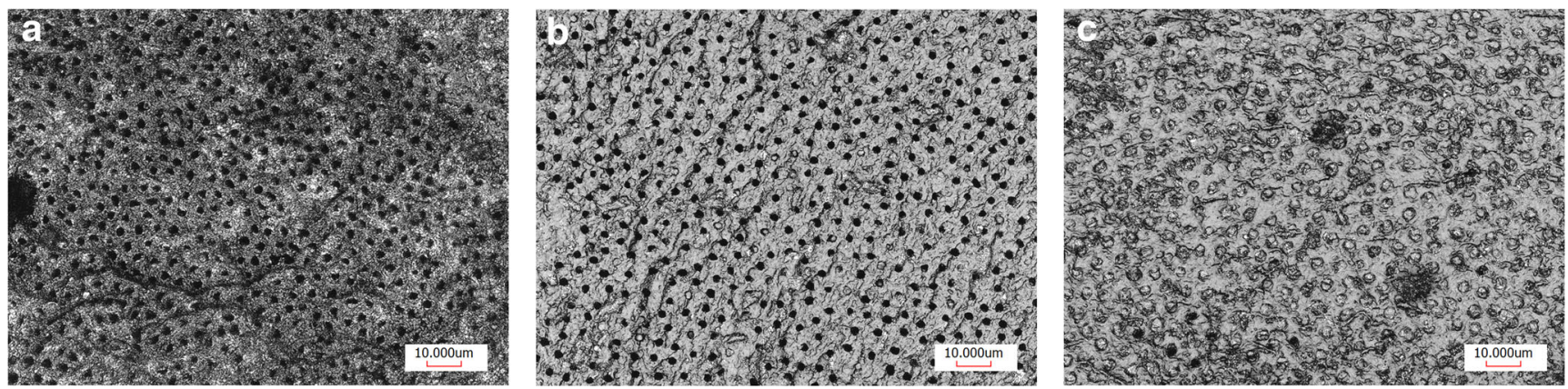

Fig. 3 a, b, c The cervical, middle, and aoucal regions of the laser group C, respectively 
Table 2 Statistical analysis comparing the overall cleanliness of the 3 groups and the apical region separately

Estimates

\begin{tabular}{|c|c|c|c|c|c|c|c|c|}
\hline Label & Estimate & Standard error & $\mathrm{DF}^{*}$ & $t$ value & $\operatorname{Pr} * *>|t|$ & Alpha & Lower & Upper \\
\hline Control vs test groups & -3.2847 & 0.1090 & 21 & -30.13 & $<0.0001$ & 0.05 & -3.5115 & -3.0580 \\
\hline $\mathrm{XP}$ vs laser & -0.1806 & 0.1259 & 21 & -1.43 & 0.1663 & 0.05 & -0.4424 & 0.08127 \\
\hline Control vs XP Endoshaper \& finisher/apical & -2.0833 & 0.2127 & 42 & -9.80 & $<0.0001$ & 0.05 & -2.5126 & -1.6541 \\
\hline Control vs laser/apical & -2.8333 & 0.2127 & 42 & -13.32 & $<0.0001$ & 0.05 & -3.2626 & -2.4041 \\
\hline $\mathrm{XP}$ vs laser/apical & -0.7500 & 0.2127 & 42 & -3.53 & 0.0010 & 0.05 & -1.1792 & -0.3208 \\
\hline
\end{tabular}

*Degrees of freedom

**Probability

too narrow for the application of the RFT2 tip in severely curved canals. We believe that further canal enlargement can endanger the dentine's integrity in extremely narrow canals and would therefore recommend, in such cases, using lower laser settings for 4 cycles as done by Al-Karadaghi et al. [23]. We also noticed that the laser tip circular movement may not be applicable in all cases of curved canals due to the severe curvature and different canal anatomy and would recommend in such cases the use of a pulling movement in the apical third of the canal, as suggested by Alamoudi et al. [37].

\section{Conclusion}

The present study reported on the effectiveness of the dual wavelength Er,Cr:YSGG and diode $940 \mathrm{~nm}$ lasers in removing the secondary smear layer containing dentin debris and sealer remnants from curved obturated root canals. Overall, no significant difference was observed between the laser group (Er,Cr:YSGG $2 \mathrm{~W}, 20 \mathrm{~Hz}, 50 \mu \mathrm{s}$ ) (diode $940 \mathrm{~nm}$ $2 \mathrm{~W}, 50 \%$ duty cycle) and the XP-Endoshaper and XPEndofinisher combined with EDTA 17\%. However, there was a significant difference between both groups in the apical third where the laser method showed a more effective debridement. Further research is recommended to examine the microbiological effect of the suggested dual wavelength method before applying in clinical scenarios.

Acknowledgements All three authors confirm that they have contributed significantly to the present research and have all read and agreed on the final version of the manuscript.

Funding Open Access funding enabled and organized by Projekt DEAL.

\section{Compliance with ethical standards}

Conflict of interest The authors declare that they have no conflict of interest.

Ethical approval This article does not contain any studies with human participants or animals performed by any of the authors.
Open Access This article is licensed under a Creative Commons Attribution 4.0 International License, which permits use, sharing, adaptation, distribution and reproduction in any medium or format, as long as you give appropriate credit to the original author(s) and the source, provide a link to the Creative Commons licence, and indicate if changes were made. The images or other third party material in this article are included in the article's Creative Commons licence, unless indicated otherwise in a credit line to the material. If material is not included in the article's Creative Commons licence and your intended use is not permitted by statutory regulation or exceeds the permitted use, you will need to obtain permission directly from the copyright holder. To view a copy of this licence, visit http://creativecommons.org/licenses/by/4.0/.

\section{References}

1. Yoon J, Cho BH, Bae J, Choi Y (2018) Anatomical analysis of the resected roots of mandibular first molars after failed nonsurgical retreatment. Restor Dent Endod 43(2):e16

2. Bergenholtz G (2016) Assessment of treatment failure in endodontic therapy. J Oral Rehabil 43(10):753-758

3. Tabassum S, Khan FR (2019) Failure of endodontic treatment the usual suspect. Eur J Dent 10(1):144-147

4. Endo MS, Ferraz CCR, Zaia AA, Almeida JFA, Gomes BPFA (2013) Quantitative and qualitative analysis of microorganisms in root-filled teeth with persistent infection: monitoring of the endodontic retreatment. Eur J Dent 7(3):302-309

5. Virdee SS, Thomas MB (2017) Practitioner's guide to gutta-percha removal during endodontic retreatment. Br Dent J 222(4):251-257

6. Ballal AV, Jaina I, Tayb FR (2016) Evaluation of the smear layer removal and decalcification effect of QMix, maleic acid and EDTA on root canal dentine. J Dent 51:62-68

7. Sjögren U, Figdor D, Persson S et al (1997) Influence of infection at the time of root filling on the outcome of endodontic treatment of teeth with apical periodontitis. Int Endod J 30:297-306

8. Byström A, Claesson R, Sundqvist G (1985) The antibacterial effect of camphorated paramonochlorophenol, camphorated phenol and calcium hydroxide in the treatment of infected root canals. Endod Dent Traumatol 1:170-175

9. Law A (2004) An evidence-based analysis of the antibacterial effectiveness of intracanal medicament. J Endod 30(10): 689-694

10. Zandi H, Petronijevic N, Ibrahimu Mdala I et al (2019) Outcome of endodontic retreatment using 2 root canal Irrigants and influence of infection on healing as determined by a molecular method: a randomized clinical trial. J Endod 45(9):1089-1098 
11. Schirrmeister JF, Wrbas KT, Meyer KM, Altenburger MJ, Hellwig E (2006) Efficacy of different rotary instruments for Gutta-Percha removal in root canal retreatment. J Endod 32(5):469-472

12. Colaco AS, Pai VA (2015) Comparative evaluation of the efficiency of manual and rotary Gutta-percha removal techniques. J Endod 41(11):1871-1874

13. Nevares G, de Albuquerque DS, Freire LG, Romeiro K, Fogel HM, dos Santos M, Cunha RS (2016) Efficacy of ProTaper NEXT compared with Reciproc in removing obturation material from severely curved root canals: a micro-computed tomography study. J Endod 42(5):803-808

14. Bürklein S, Benten S, Schäfer E (2013) Shaping ability of different single-file systems in severely curved root canals of extracted teeth. Int Endod J 46(6):590-597

15. Arslan H, Topcuoglu HS, Karatas E, Barutcigil C, Aladag H, Topcu KM (2012) Effect of the smear layer in the removal of calcium hydroxide from root canal walls. J Conserv Dent 15(2):113-117

16. Keleș A, Köseoğlu M (2009) Dissolution of root canal sealers in EDTA and NaOCl solutions. J Am Dent Assoc 2009 140(1):74-79

17. Nogueira RD, Silva CB, Lepri CP, Palma-Dibb RG, GeraldoMartins VR (2017) Evaluation of surface roughness and bacterial adhesion on tooth enamel irradiated with high intensity lasers. Braz Dent J 28(1):24-29

18. Yamazaki R, Goya C, Yu DG et al (2001) Effects of erbium, chromium: YSGG laser irradiation on root canal walls: a scanning electron microscopic and thermographic study. J Endod 27(1):9-12

19. George R, Meyers IA, Walsh LJ (2008) Laser activation of endodontic irrigants with improved conical laser fiber tips for removing smear layer in the apical third of the root canal. J Endod 34(12): $1524-1527$

20. Franzen R, Esteves-Oliveira M, Meister J, Wallerang A, Vanweersch L, Lampert F, Gutknecht N (2009) Decontamination of deep dentin by means of erbium, chromium:yttriumscandiumgallium-garnet laser irradiation. Lasers Med Sci 24(1): 75-80

21. Peeters HH, Suardita K (2011) Efficacy of smear layer removal at the root tip by using ethylenediaminetetraacetic acid and erbium, chromium: yttrium, scandium, gallium garnet laser. J Endod 37(11):1585-1589

22. Schoop U, Kluger W, Dervisbbegovic S (2006) Innovative wavelengths in endodontic treatment. Lasers Surg Med 38:438-441

23. Al-Karadaghi TS, Franzen R, Jawad HA et al (2015) Investigations of radicular dentin permeability and ultrastructural changes after irradiation with Er,Cr:YSGG laser and dual wavelength (2780 and $940 \mathrm{~nm}$ ) laser. Lasers Med Sci 30(8):2115-2121

24. Nasher R, Hilgers RD, Gutknecht N (2020) Debris and smear layer removal in curved root canals using the dual wavelength $\mathrm{Er}, \mathrm{Cr}$ : YSGG/diode $940 \mathrm{~nm}$ laser and the XP-Endoshaper and finisher technique. Photobiomod Photomed Laser Surg 38(3):174-180

25. Nasher R, Gutknecht N (2020) Temperature changes on the surface of curved root canals during endodontic debridement and disinfection with a dual wavelength laser Er,Cr:YSGG and diode $940 \mathrm{~nm}$ protocol. Lasers Dent Sci 4:67-71

26. Hülsmann M, Rümmelin C, Schäfers F (1997) Root canal cleanliness after preparation with different endodontic handpieces and hand instruments: a comparative SEM investigation. J Endod 23: 301-306

27. Stabholz A, Friedman S (1988) Endodontic retreatment-case selection and technique, part 2: treatment planning for retreatment. J Endod 14(12):607-614

28. Hülsmann M, Bluhm V (2004) Efficacy, cleaning ability and safety of different rotary NiTi instruments in root canal retreatment. Int Endod J 37(7):468-476

29. Alves FR, Marceliano-Alves MF, Sousa JC et al (2016) Removal of root canal fillings in curved canals using either reciprocating singleor rotary multi-instrument systems and a supplementary step with the XP-Endo finisher. J Endod 42(7):1114-1119

30. Latheef AA, Miglani R, Indira R et al (2016) Effect of passive ultrasonic irrigation on the cleanliness of dentinal tubules in nonsurgical endodontic retreatment with and without solvent: a scanning electron microscope study. J Int Oral Health 8(7):753-759

31. Silva EJNL, Belladonna FG, Zuolo AS, Rodrigues E, Ehrhardt IC, Souza EM, de-Deus G (2018) Effectiveness of XP-endo finisher and XP-endo finisher $\mathrm{R}$ in removing root filling remnants: a microCT study. Int Endod J 51:86-91

32. Alves FRF, Marceliano-Alves MF, Sousa JCN et al (2016) Removal of root canal fillings in curved canals using either reciprocating single- or rotary multi-instrument systems and a supplementary step with the XP-Endo finisher. J Endod 42(7):1114-1119

33. Vergauwen TE, Michiels R, Torbeyns D et al (2014) Investigation of coronal leakage of root fillings after smear layer removal with EDTA or Er,Cr:YSGG laser through capillary flow porometry. Int J Dent:593160

34. Erben P, Chang AM, Darveau RP, Fong H, Johnson JD, Paranjpe A (2019) Evaluation of the bactericidal potential of 2780-nm ER,CR: YSGG and 940-nm diode lasers in the root canal system. Laser Dent Sci 3:137-146

35. Gutknecht N, Al-Karadaghi TS, Al-Maliky MA et al (2016) The bactericidal effect of 2780 and $940 \mathrm{~nm}$ laser irradiation on enterococcus faecalis in bovine root dentin slices of different thicknesses. Photomed Laser Surg 34(1):11-16

36. Hartmann RC, Fensterseifer M, Peters OA, de Figueiredo JAP, Gomes MS, Rossi-Fedele G (2018) Methods for measurement of root canal curvature: a systematic and critical review. Int Endod J 52(2):169-180

37. Alamoudi G, Haidary D, Gutknecht N (2019) Effects of Er,Cr: YSGG laser and radial firing tips in dye removal from simulated curved canals: visualization study. Laser Dent Sci 3(1):31-36

Publisher's note Springer Nature remains neutral with regard to jurisdictional claims in published maps and institutional affiliations. 